
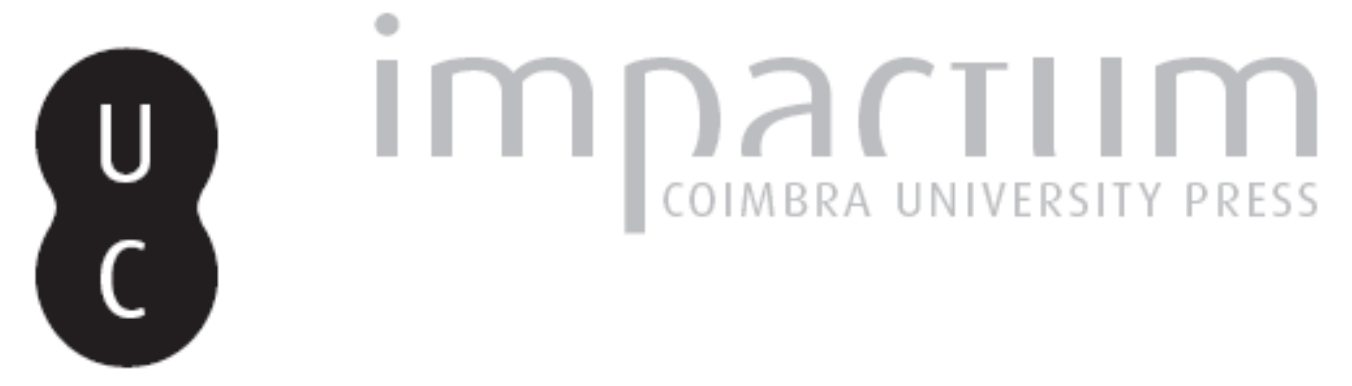

\title{
Observações sobre o circuito de arte digital no Brasil
}

\section{Autor(es): $\quad$ Gasparetto, Débora Aita}

Publicado por: Centro de Literatura Portuguesa; Imprensa da Universidade de Coimbra

URL persistente:

URI:http://hdl.handle.net/10316.2/37794

DOI:

DOI:http://dx.doi.org/10.14195/2182-8830_3-1_13

Accessed : $\quad$ 26-Apr-2023 14:12:15

A navegação consulta e descarregamento dos títulos inseridos nas Bibliotecas Digitais UC Digitalis, UC Pombalina e UC Impactum, pressupõem a aceitação plena e sem reservas dos Termos e Condições de Uso destas Bibliotecas Digitais, disponíveis em https://digitalis.uc.pt/pt-pt/termos.

Conforme exposto nos referidos Termos e Condições de Uso, o descarregamento de títulos de acesso restrito requer uma licença válida de autorização devendo o utilizador aceder ao(s) documento(s) a partir de um endereço de IP da instituição detentora da supramencionada licença.

Ao utilizador é apenas permitido o descarregamento para uso pessoal, pelo que o emprego do(s) título(s) descarregado(s) para outro fim, designadamente comercial, carece de autorização do respetivo autor ou editor da obra.

Na medida em que todas as obras da UC Digitalis se encontram protegidas pelo Código do Direito de Autor e Direitos Conexos e demais legislação aplicável, toda a cópia, parcial ou total, deste documento, nos casos em que é legalmente admitida, deverá conter ou fazer-se acompanhar por este aviso.

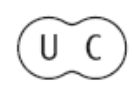




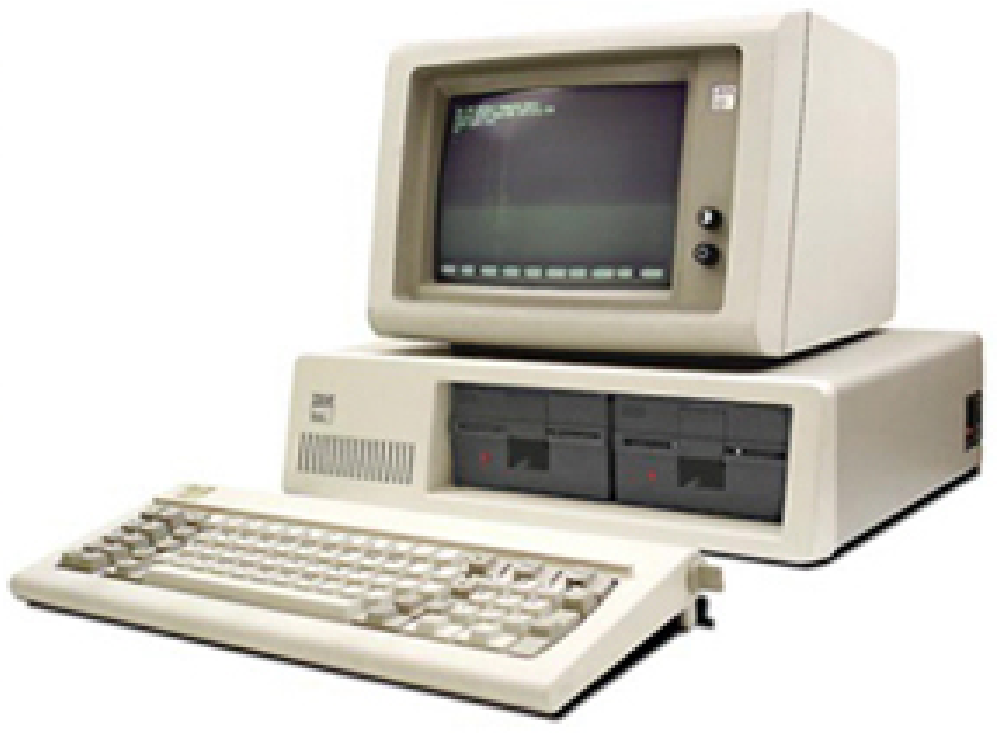

Vol. 3.1 (2015)

ISSN 2182-8830

'Artes, Média e Cultura Digital'

Paulo Silva Pereira e Pedro Serra (orgs.) 


\section{Observações sobre o Circuito de Arte Digital no Brasil DÉBORA AITA GASPARETTO}

\section{Introdução}

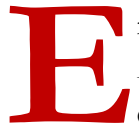

m 2014, na publicação intitulada O Curto-Circuito da Arte Digital no Brasil, realizamos um mapeamento dos espaços de produção distribuição - consumo - preservação da arte digital no país. $\mathrm{O}$ presente texto é um recorte deste mapeamento, com foco nos artistas que trabalham na interface da arte-ciência-tecnologia, em projetos que envolvem computabilidade, interatividade, virtualidade, imersão e "tempo real", em pesquisas relacionadas com a biotecnologia, nanotecnologia, física, computação, matemática, engenharias, mecânica, robótica, entre outras áreas, interfaceadas pelas mídias digitais.

A arte digital tem especificidades produtivas e expositivas, relacionadas ao mercado, ao colecionismo e à preservação, que a diferem do vídeo e da fotografia. Por isso, é primordial enfatizar que o termo "arte digital" é abordado neste texto como uma estratégia de inserção política, pois de certo modo, já foi legitimado pelo MINC (Ministério da Cultura), quando este cria uma Setorial específica para a arte digital, o que legitima um campo e abre a possibilidade de incentivos e editais específicos. Este espaço constituído junto ao MINC é resultado de um trabalho contínuo (desde 2004) por parte de artistas, teóricos e pesquisadores da área junto ao governo. O cenário da arte digital no Brasil ainda é de pouco incentivo e esta produção circula, é consumida e legitimada, ainda às margens do tradicional sistema da arte contemporânea, encontrando um circuito particular que tem atendido suas necessidades produtivas, no âmbito das universidades; expositivas, no âmbito dos festivais; e de preservação, com algumas poucas instituições, como o FILE (Festival Internacional de Linguagem Eletrônica) e seu acervo virtual, além do Itaú Cultural, que preserva um pequeno, mas representativo acervo de obras digitais.

\section{Um Recorte sobre a Produção em Arte Digital no Brasil}

Há uma representativa e diversificada produção brasileira, com alguns nomes que se destacam no cenário internacional, fazendo parte da história da arte digital brasileira como Waldemar Cordeiro, artista da primeira geração a trabalhar com computadores ainda nos anos 1960. Entre a extensa lista de artistas nacionais consagrados destacamos Anna Barros (in memoriam), traba- 
lhando com nanoarte; Eduardo Kac, artista que atualmente reside fora do país e trabalha com telepresença e bioarte; Suzete Venturelli e o Grupo Mídia Lab da UNB, trabalhando com arte computacional, software art, arte generativa e hacktivismo; a equipe interdisciplinar SCIArts, também explorando diversas linguagens da arte interativa em instalações que envolvem robótica, por exemplo; Diana Domingues, com o extinto grupo Artecno, trabalhando com instalações interativas e imersivas; Tania Fraga, investigando neurociência e a construção de ambientes virtuais imersivos. Estes artistas fazem parte da história da arte digital no Brasil, assim como Gilbertto Prado e o Grupo Poéticas Digitais, escolhido para representar a região Sudeste do Brasil no presente texto.

Outros artistas não menos representativos - mas que conforme as considerações do artista Milton Sogabe fazem parte da terceira geração ${ }^{1}$ de artistas nacionais a trabalhar com as tecnologias digitais - se interessam pela robótica e pelos organismos artificiais híbridos, como Guto Nóbrega, que trabalha a partir da sua pesquisa com plantas robóticas. A natureza e sua potencialidade poética também faz parte do trabalho de Maria Luiza Fragoso, coordenadora do Grupo Nano, ao lado de Guto Nóbrega. Giselle Beiguelman também tem uma produção reconhecida internacionalmente, com obras em web art e glitch art. Já Lucas Bambozzi dedica-se à mobile art e Anaisa Franco, às esculturas sensitivas, que reagem à presença do público. Também trabalhando com esculturas destacamos o trabalho de Soraya Braz e Fábio Fon, com impressão 3D e a desmaterialização crítica de objetos. Em contrapartida, Fábio Fon também realiza obras em web art. Já Edgar Franco utiliza-se dos recursos tecnológicos e digitais para amplificar sua crítica em obras relacionadas com a estética cyberpunk.

Entre alguns dos raros artistas brasileiros representados por galerias destacamos: Gisela Motta \& Leandro Lima, Fernando Velásquez, Kátia Maciel e Lucas Bambozzi. Ainda é preciso reconhecer alguns artistas como Rejane Cantoni e Daniela Kutschat, as quais têm obras que integram o acervo do ZKM (Centro de Arte e Mídia de Karlsruhe) e também do Itaú Cultural e conseguem uma inserção maior no sistema da arte contemporânea. Pode-se dizer que tais artistas atuam no "entre", transitam pelos dois "sistemas" (arte digital e arte contemporânea) e carregam características de ambos. Nesta terceira geração ainda há aqueles artistas que se desvinculam das universidades e misturam-se à cultura digital e à música. Entre estes podemos citar o trabalho de Jarbas Jácome, representando o vínculo com a cultura digital e dos softwares livres, bem como o trabalho de Henrique Roscoe e do Vj Spetto, estes mais voltados ao universo da música eletrônica.

No Brasil, mesmo que polos produtores se destaquem, como a região Sudeste e a Centro-Oeste, sobretudo Brasília e Goiás, podemos perceber que

1 Para mais informação sobre as gerações da arte e tecnologia brasileira consulte Sogabe (2009). Ou ainda, Gasparetto (2014c). 
a arte digital, entendida como sistema complexo, tem ganhado espaço junto aos jovens artistas do Brasil inteiro. Para este texto aprofundamos as obras/projetos/trabalhos de apenas um artista de cada região brasileira, mesmo tendo em mente outros nomes de tamanha representatividade, alguns citados anteriormente. Mesclamos aqui jovens artistas, com produções relevantes, com aqueles já consagrados no mundo da arte digital, ressaltando características específicas da produção nacional. Gilbertto Prado e o Grupo Poéticas Digitais representam a região Sudeste e a história da arte digital brasileira, trabalhando com diversas linguagens, das quais no presente texto destacamos as mídias móveis; Alberto Semeler representa a região Sul e as pesquisas mais recentes em neuroarte; Márcio Mota está associado à região Centro-Oeste e à produção que tem se disseminado pelo país em videomapping. Assim como ele, Roberta Carvalho também trabalha com projeções mapeadas e é a representante da região Norte. E Ricardo Brazileiro representa a região Nordeste, trabalhando com softwares livres e cultura digital. A poética de tais artistas levanta questões que são particulares de nosso país, como a relação com a natureza, com as memórias de nosso povo, nossa ironia e crítica.

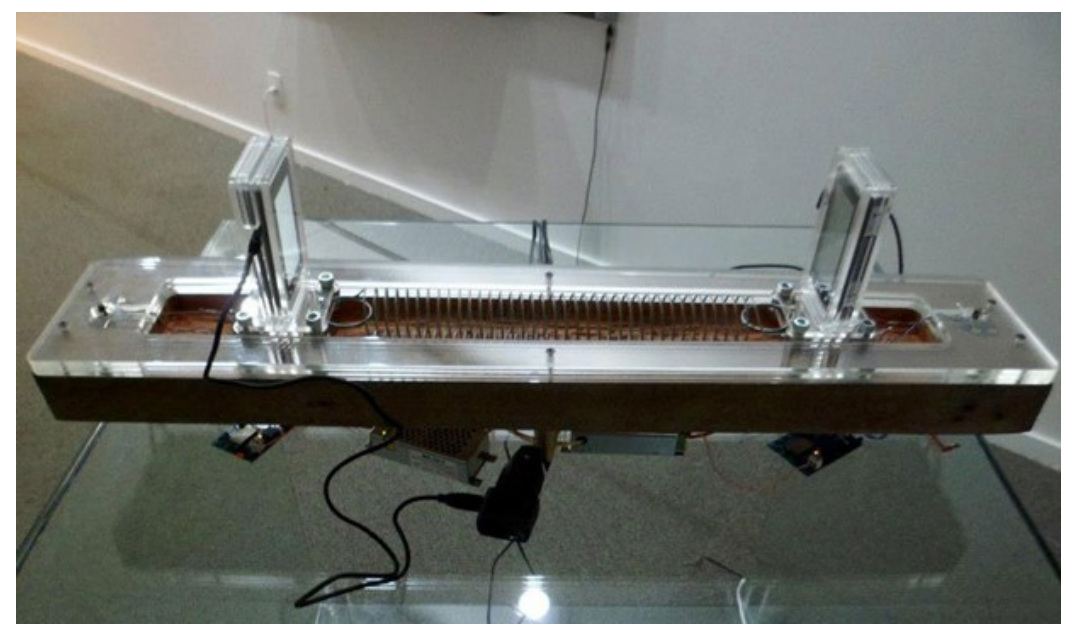

(C) Gilbertto Prado, Encontros (2012).

Gilbertto Prado² e o Grupo Poéticas Digitais, escolhem contar as histórias invisíveis das cidades, por meio da arte digital. Ele é artista multimídia e professor junto à ECA-USP, onde coordena o Grupo Poéticas Digitais. Contemplado no Rumos Itaú Cultural e premiado por instituições como o Prêmio Sergio Motta de Arte e Tecnologia, o artista já expôs nas Bienais de São Paulo e do Mercosul, no contexto brasileiro; na Bienal Arte Nuevo InteractivA, no México; no Museum of the City of Skopje, na Macedonia; no Museo

2 http://www.gilberttoprado.net/gilberttoprado/info.html 
Nacional de Arte Contemporáneo Reina Sofía, em Madrid, entre outras mostras relevantes. Gilbertto é autor do livro Arte telemática: dos intercâmbios pontuais aos ambientes virtuais multiusuário (2003). ${ }^{3} \mathrm{O}$ Grupo Poéticas Digitais forma-se em 2002, composto por professores, artistas e alunos da USP, mas não é um grupo permanente, ganhando composições distintas para cada projeto. Entre alguns dos componentes estão Agnus Valente, Andrei Thomaz, Claudio Bueno, Ellen Nunes, Leonardo Lima, Luciana Ohira, Maria Luiza Fragoso, Maurício Trentin, Nardo Germano, Renata La Rocca e Sérgio Bonilha.

Entre as obras produzidas por Gilbertto Prado e seu grupo destacamos Encontros (2012). ${ }^{4}$ Aqui os dispositivos móveis são utilizados para falar de aproximação, seja entre as águas do rio Amazonas, seja entre pessoas que buscam pela palavra "encontro" na internet. A obra assume no espaço expositivo a forma de uma escultura, onde os dois smartphones, que exibem os vídeos em loop das águas do rio em tonalidades diferentes (de um lado uma água preta e do outro uma água marrom), são separados por molas tensionadas conforme o fluxo de dados gerado pela palavra "encontro", pela condição das marés e das fases da lua. Duas placas de Arduíno Bluetooth permitem essa troca de dados, aqui a interatividade pode acontecer por parte do público ao gerar dados nos sistemas de busca com a palavra-chave, mas há outra interatividade que nos rodeia e nem sempre é perceptível, aquela proporcionada pela natureza e seu fluxo, transformado em dados. Para cada ação, uma reação.

Também o trabalho ZN:PRDM (Zona Neutra: Passa um Rio Dentro de Mim) $(2013)^{5}$ merece uma aproximação maior, o grupo vai à periferia de São Paulo percorrer o caminho invisível das águas, com a ajuda de radiestesistas e de mapas existentes. Tal caminho, depois de mapeado, podia ser ouvido via dispositivos móveis, enquanto fosse percorrido. Aqui a tecnologia da mobilidade serve para ampliar os sentidos humanos, ativando memórias dos espaços invisíveis que nos cercam. Por onde passava o grupo deixava marcas (grafites), as quais lembravam aos moradores que naquele lugar ainda havia a influência da força das águas.

Gilbertto Prado, é um dos primeiros artistas a trabalhar com arte digital no Brasil, tendo dado seus primeiros passos com a arte postal, ainda nos anos 1980. O seu trabalho está associado a temáticas bastante exploradas pelos artistas brasileiros, como a relação do homem com a natureza, destacando de modo sempre poético o que é invisível, inaudível ou ainda imperceptível. Aqui a tecnologia possibilita ver, ouvir e perceber essa arte, integrando o sistema complexo que é a obra. Assim como a grande maioria dos artistas brasileiros que trabalham com arte digital, sua produção está associada à universidade.

3 https://poeticasdigitais.files.wordpress.com/2009/09/2003-

arte_telematica_dos_intercambios_pontuais_aos.pdf

4 http://www.poeticasdigitais.net/POETICAS/encontros.html

${ }^{5}$ http://www.gilberttoprado.net/gilberttoprado/znprdm.html 
Alberto Semeler também está vinculado à universidade, como professor na UFRGS (Universidade Federal do Rio Grande do Sul). O artista está interessado na fisiologia do ser humano e suas obras visam provocar reações fisiológicas no público, por meio da arte abjeta. $\mathrm{O}$ artista inicia suas investigações em meados dos anos 1980, com videoperformance, arte abjeta e mórbida, quando trabalhava com arte matérica e efêmera, reciclando plásticos quimicamente, usando látex e cabelos humanos. Ele aprofunda-se, com o passar dos anos, em arte interativa e, atualmente, tem pesquisado softwares interativos, como o Processing e softwares de CAD para impressão de objetos em $3 \mathrm{D}$ a fim de construir seres robóticos como drones.

Em Objeto tecnopoético (2014) o público interage com a projeção de caveirinhas, moscas e larvas que dançam sobre os exames de imagem de corpos humanos em 3D, conforme a música que é tocada pelo próprio interator em um teclado eletrônico. Em uma narrativa não-linear e lúdica, cenas mórbidas tratam do quão humano e perecíveis somos. Aqui natural e artificial também compõem uma experiência lúdica e crítica.

Já em Gamearte: Artista-Hospedeiro/Espectador-Cobaia (2012), Alberto divide a autoria de seu trabalho com o Laboratório de Pesquisas em Tecnopoéticas, Cognição e Educação, que coordena junto à UFRGS. Nesta oportunidade é o artista quem brinca com o público, tentando manipulá-lo, ao mesmo tempo em que este interage com a obra por meio de um tapete digital que altera a projeção a sua frente. Para esta obra o artista trabalha com a reutilização de tecnologias (Device Art) visando reapropriações estéticas. Por meio da neuroarte e de investigações sobre o que há de mais recente em pesquisas de neurociência, Alberto trabalha imageticamente o maior produtor de histórias do mundo, o cérebro humano. Suas obras buscam ativar experiências sensório-visuais, as quais são um processo neurofisiológico e bioquímico. ${ }^{6}$

Trabalhando com narrativas e projeção mapeada em esculturas de bonecos de gesso compradas em lojas de artesanato, Márcio H. Mota tem desenvolvido uma representativa produção. O jovem artista, que é mestre em Artes e Tecnologia pela UNB (Universidade de Brasília), vive e trabalha em Brasília (DF) e participa do Tuttaméia, onde realiza trabalhos com Fernando Aquino. O coletivo foi indicado ao Prêmio Pipa em 2013. Márcio também tem uma produção individual e é atuante nos festivais de arte e tecnologia. Entre os softwares utilizados pelo artista no processo de produção de suas obras estão o Modul8 e o MadMapper. Na videoinstalação Espião (2013), ${ }^{7}$ que faz parte da série Objetos de Estimação, um boneco de gesso tem seu corpo animado por uma corrente de fluxos luminosos e o próprio rosto do artista, projetado sobre o rosto do boneco, vivifica as críticas relacionadas à espionagem norte-

6 Para outras informações sobre a neuroarte de Alberto Semeler, acesse: https://www.medialab.ufg.br/art/anais/textos/AlbertoSemeler.pdf

7 https://vimeo.com/74697479 
americana nos outros países. O discurso proferido pelo boneco soa como ironia poética:

Imagina se todo espelho que tu passaste pela frente guardasse tuas imagens Quantas faces angulosas de ti não teríamos

Um dado multifacetado

corruptela de gente

facebook, youtube, google mapping

de tudo grada um pouco

vou botar-lhe no meio de minhas lombadas

ensinar-te muito bem minha risada

pra um dia eu cometer seu suicídio (...) ${ }^{8}$

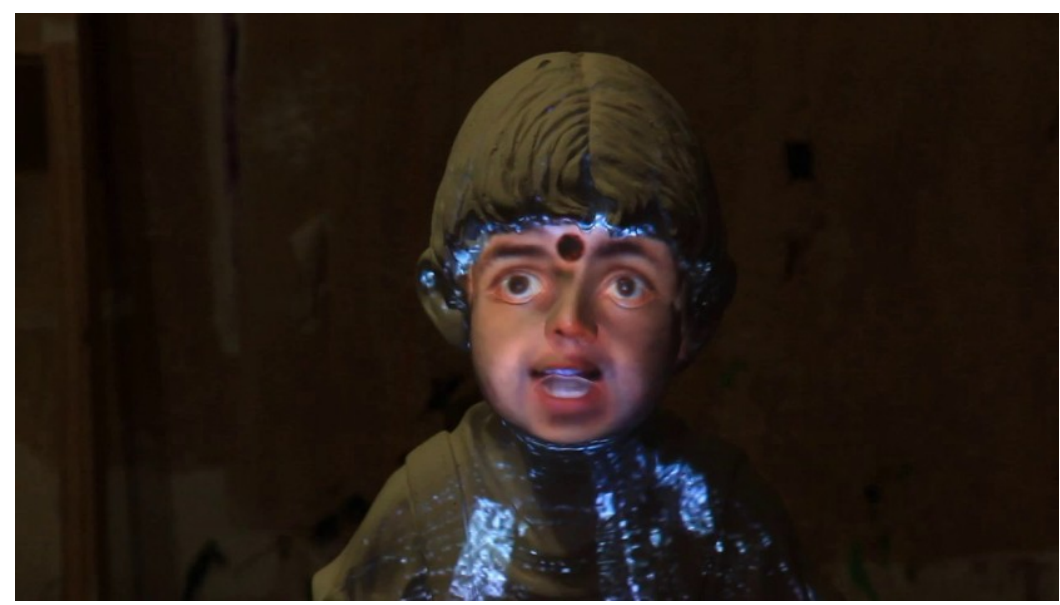

(C) Márcio H. Mota, Espião (2013).

Outras obras $^{9}$ do artista envolvem a projeção de uma bailarina em vapor d'água ou pequenas projeções mapeadas em objetos cotidianos, como garrafas de vidro, todas carregando um misto de magia, fantasmagoria e encantamento. Mas se as projeções de Márcio H. Mota nos remetem a tempos passados, onde o cinema reinava absoluto, suas narrativas estão completamente inseridas no contexto contemporâneo.

${ }^{8}$ http://repositorio.unb.br/bitstream/10482/17292/1/2014_MarcioHofmannMota.pdf

${ }^{9}$ https://vimeo.com/103682147 


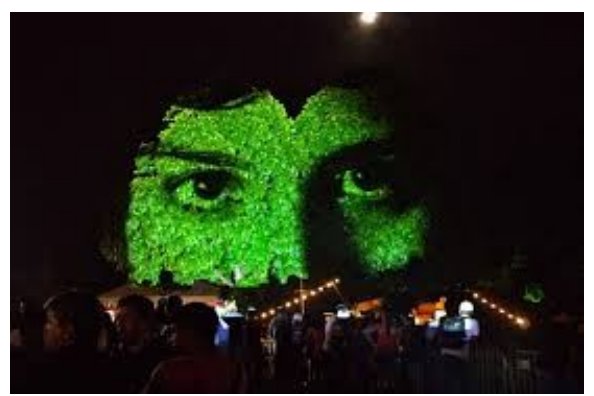

(C) Roberta Carvalho, Symbiosis (2007-).

As projeções mapeadas têm ganhado espaço também no trabalho de Roberta Carvalho, jovem artista da região Norte do país (Belém-PA) que já ganhou diversos prêmios, entre eles o Prêmio Funarte Mulheres nas Artes Visuais (2014). Roberta é também idealizadora do Festival Amazônia Mapping. ${ }^{10}$ No projeto Symbiosis, ${ }^{11}$ o qual ela mantém desde 2007, Roberta dá vida às árvores de espaços públicos ao projetar sobre suas copas o rosto dos ribeirinhos das comunidades que vivem à beira do Rio no Pará. Aos poucos, imagens (fotografia e vídeo digital) vão transformando o cenário da cidade, levando luz à natureza e deixando esta fazer-se perceber. Conforme as palavras da artista: "Fato é que essas imensas esculturas verdes e iluminadas provocam, no passante e/ou no fruidor da obra, uma espécie de susto, de medo, como aquele misto de espanto e magia que sentiram aqueles que experimentaram as primeiras exibições de cinema em fins do século XIX.” Entre os softwares utilizados por Roberta estão o Modul8, o Madmapper, e o Syphoner.

E do Nordeste, escolhemos o artista pernambucano Ricardo Brazileiro, o qual tem uma ligação muito próxima com os laboratórios livres de estudo de softwares e gambiarras. Ele é mestre em Ciências da Computação pela UFP (Universidade Federal de Pernambuco) e um dos fundadores do Lab3E. ${ }^{12}$ Seu trabalho artístico envolve diversas instalações sonoras, imersivas e interativas, com o uso de variadas plataformas e computação ubíqua e ainda o desenvolvimento de softwares como o tAMARINO, usado para prototipagem rápida de instalações artísticas na Internet. Em seu projeto 3:CO Ecossistema do Sensitivo (2011), ${ }^{13}$ ele coleta dados do meio ambiente e da urbe em tempo real e esses dados transformam-se em informações que ativam guarda-chuvas capazes de reagir ao entorno. Esses "ecossistemas híbridos" tornam visíveis os desequilíbrios ecológicos. Já, em um dos seus projetos mais recentes, Contos de Ifá (2014), um web game educativo, Ricardo trata da

\footnotetext{
10 http:/ / amazoniamapping.com/

11 https://www.youtube.com/watch?v=tyzSofHqfxA\&t=11

12 http://labs.3ecologias.net/

13 http://3eee.co/
} 
mitologia brasileira por meio do jogo. O site, ${ }^{14}$ construído com software livre, aborda as histórias dos orixás: Exu, Ogun, Oxóssi e Omolu, histórias essas trazidas da África ao Brasil e que já fazem parte da memória coletiva do nosso povo.

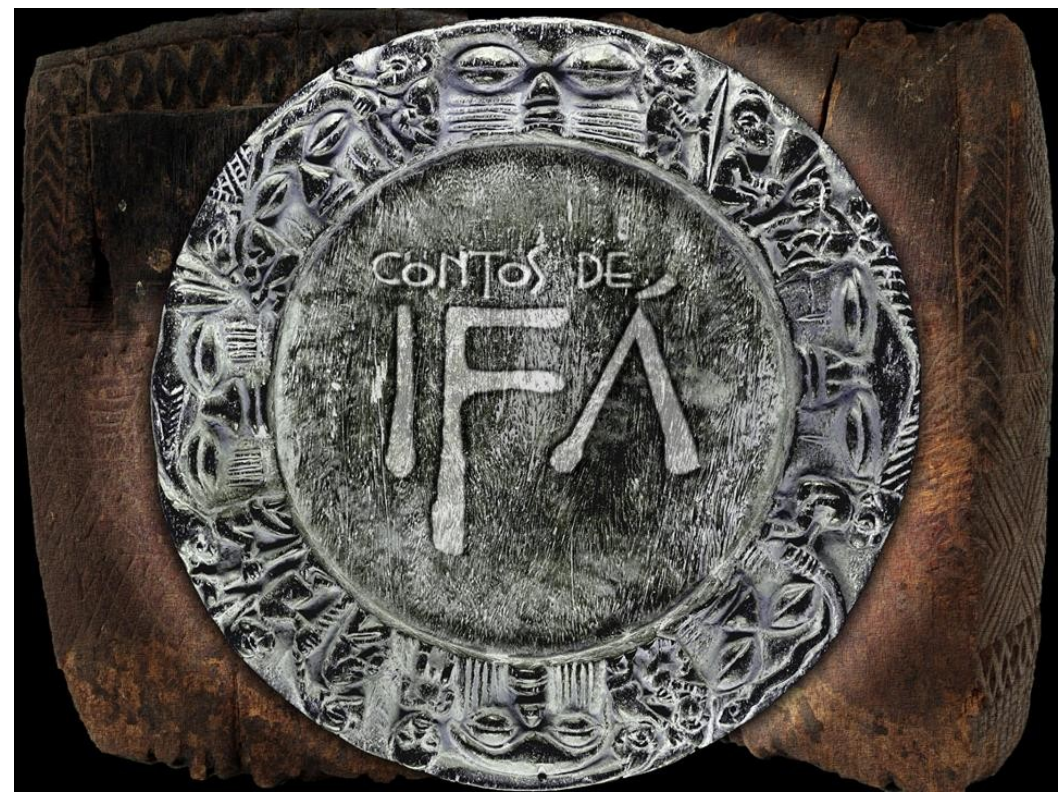

(C) Ricardo Brazileiro, Contos de Ifá (2014).

\section{Arte Digital e os Sistemas de Arte no País}

É importante demonstrar que mesmo com uma produção representativa, grande parte dos artistas brasileiros que trabalham com arte digital ainda não conquistou espaço cativo nas principais Bienais Brasileiras como a de São Paulo e do Mercosul, mesmo que inserções pontuais tenham ocorrido. Por uma questão de preconceito de ambos os lados (arte digital e arte contemporânea), de falta de infraestrutura, falta de conhecimento, falta de diálogos, acreditamos que a arte digital desenvolve-se independentemente do mercado ou do mainstream, e de modo genuíno em um sistema particular, que apresenta fortes antecedentes históricos, é composto por agentes que têm formação híbrida (artes, comunicação, design, literatura, cultura digital). Em Arte-ciênciatecnologia: o sistema da arte em perspectiva (2014), tivemos a oportunidade de entrevistar 29 pesquisadores, artistas e curadores brasileiros, bem como 5 internacionais, buscando compreender o modo como eles percebem a inserção da arte digital no sistema da arte contemporânea, o fomento à produção, os espaços expositivos e as demandas da arte digital. Embora suas opiniões

14 http://contosdeifa.com/ 
muitas vezes sejam divergentes, o que é consenso entre os entrevistados (Gasparetto, 2014b) é que o sistema da arte contemporânea não atende as demandas expositivas da arte digital. Ao mesmo tempo, estruturas de legitimação são organizadas, paralelas àquelas do sistema da arte contemporânea e em determinados momentos em diálogo com elas.

Entre estas estruturas cabe destacar os seguintes festivais e eventos: FILE - Festival Internacional de Linguagem Eletrônica (2000-, São Paulo e descentralizado), o Emoção Art.ficial - Bienal Internacional de Arte e Tecnologia do Itaú Cultural (2002-2012, São Paulo), o \#.ART - Encontro Internacional de Arte e Tecnologia, desde 1989, mas anualmente a partir de 2007, em Brasília, o On_Off (2005-, São Paulo), o Vivo Arte.Mov (2006-2012, Belo Horizonte e descentralizado), o Simpósio de Arte Contemporânea PPGART/UFSM, que em diversas edições esteve direcionado à arte e tecnologia (2006-, Santa Maria) e que em 2014 traz o FACTORS 1.0 - Festival de Arte Ciência e Tecnologia do RS, o FAD - Festival de Arte Digital (2007-, Belo Horizonte), a Mlc Mostra Live Cinema (2007-, Rio de Janeiro), o FAM - Festival Internacional de Arte e Mídia (2009-2010, Brasília), o Continuum Festival de Arte e Tecnologia do Recife (2009-), o FAT - Festival de Arte e Tecnologia (2009-, Mato Grosso do Sul), a Mostra 3M de Arte Digital (2010-, São Paulo), o Hiperorgânicos - Simpósio Internacional e Laboratório Aberto de Pesquisa em Arte, Hibridação e Biotelemática (2010-, Rio de Janeiro), o Encontro Internacional de Grupos de Pesquisa: "Convergências entre Arte, Ciência, Tecnologia \& Realidades Mistas” - Latitudes-Atitudes (2010-, São Paulo), o Salão Xumucuís de Arte Digital (2011-, Belém), o 10 Dimensões: Diálogos em rede, corpo, arte e tecnologia (2011-, Natal), o SP_Urban Digital Festival (2012-, São Paulo), o SIIMI - Simpósio Internacional de Inovação em Mídias Interativas (2012-, Goiás), FAM - Festival Amazônia Mapping (2013-, Belém), Reconvexo - Festival Nacional de Vídeo-Projeções Mapeadas (2013-, Recôncavo Baiano), Tropixel - Arte, Ciência, Tecnologia e Sociedade (2013, Juiz de Fora e Ubatuba), o \# FIART - Festival Internacional de Arte e Tecnologia (2014, Brasília) e o Podfest - Festival de Poéticas Digitais (2014, Rio de Janeiro). Para citar algumas "faíscas" do circuito expositivo da arte digital brasileira.

Estes eventos demonstram que em diferentes regiões do país há um circuito de produção-exposição associado e independente dos tradicionais circuitos da arte contemporânea. Normalmente são os próprios artistas, curadores ou entusiastas que já têm um conhecimento teórico, ao menos, em arte digital, que articulam este circuito e também circulam entre os eventos citados. É nestes locais que acontece o consumo da produção em arte digital, em nível de experiência ao interator, não de consumo no sentido tradicional. Então podemos perceber que essa rede tem agentes distintos daqueles que circulam no sistema mainstream da arte contemporânea (museus, galerias, feiras de arte, bienais). 


\section{Considerações Finais}

Enfim, esperamos que este breve relato sobre a produção em arte digital no Brasil possa demonstrar uma parcela do significativo trabalho que tem sido realizado por aqui. Outras informações sobre artistas e festivais do gênero no país você encontra na publicação "O curto-circuito da arte digital no Brasil" (Gasparetto 2014a). Estes lugares transitórios, no qual é produzida, circula, é legitimada, consumida e exposta a arte digital, dialogam com o nosso entendimento de sistema da arte na atualidade. Assim, mesmo com um déficit em relação ao incentivo financeiro, o que ocasiona inconstância de incentivos, ausência de centros especializados ou infraestruturas mais consistentes a ponto de manter e preservar as obras/projetos/trabalhos, a arte digital mantém um campo teórico e prático especializado, mantém agentes específicos, lugares transitórios sim, mas também particulares. O consumo, como observamos, está em diálogo com a cultura digital e acontece a cada experiência do público com a obra, mas em termos financeiros pode seguir a rede e entrar em um mercado internacional. As instituições legitimadoras já foram os espaços como o Itaú Cultural, o Instituto Sergio Motta, o MIS-SP e agora são as universidades, como ocorre em outros países, mas também os festivais, os próprios pares e algumas instituições remanescentes como o Oi Futuro. E a preservação segue o encalço do sistema internacional, mais voltada às discussões e com poucos exemplos na prática.

\section{Referências}

GASPARETTO, Débora Aita (2014a). O “curto-circuito" da arte digital no Brasil. Santa Maria: Edição do Autor. 29 Maio 2015. http:/ / artedigitalbr.wix.com/ circuito org. (2014b). Arte-ciência-tecnologia: o sistema da arte em perspectiva. Santa Maria: Editora Lab Piloto. 29 Maio 2015. http://www.academia.edu/7883254/Arte-ci\%C3\%AAnciatecnologia_o_sistema_da_arte_em_perspectiva (2014c). "Arte-ciência-tecnologia e sistemas da arte na era da cultura digital: contexto Brasil." Palíndromo 6.11: 79-97. 29 Maio 2015. DOI: $10.5965 / 2175234606112014079$.

SOGABE, Milton (2009). "Arte-tecnologia no Brasil: tecnologias e gerações.” III Simpósio Nacional ABCiber - ESPM/SP.

(C) 2015 Débora Aita Gasparetto.

Licensed under the Creative Commons Attribution-NoncommercialNo Derivative Works 4.0 International (CC BY-NC-ND 4.0). 